
Non-Managerial Employees in Selected Apparel Organizations in Gampaha District, Sri

\title{
Lanka
}

\author{
Sankalpana, WAS and Jayasekara, P
}

\begin{abstract}
Area of the Study

As a significant determinant of job satisfaction of an employee, this study is to discuss the impact of organizational rewards on job satisfaction of non-managerial employees in the selected apparel organizations.

\section{Problem of the Study}

This research study attempts to explore the impact of organizational rewards to job satisfaction of non- managerial employees in selected apparel organizations in Gampaha district. Thus, the research problem of this study was; "Do the organizational rewards have an impact on job satisfaction of non-managerial employees in selected apparel organizations in Gampaha district, Sri Lanka.
\end{abstract}

\section{Method of the Study}

The data were collected from a convenience sample of 120 non-managerial employees in the apparel industry with a structured questionnaire consisted of 30 questions with five point Likert scales. Univariate analysis as well as bivariate analysis applied to analyzed data with the SPSS 16.0 (Version).

\section{Findings of the Study}

The results of the study emphasize that there is a positive impact of organizational rewards on employee job satisfaction. Also, it was proved that there is a significant strong positive impact of intrinsic, extrinsic rewards on non- managerial employee job satisfaction. In addition, the findings proved that age and gender do not mediate any relationship between organizational rewards and job satisfaction of non-managerial employees.

\section{Conclusion of the Study}

It is concluded that both intrinsic and extrinsic rewards are significant predictors of employee job satisfaction and both can be used to enhance the level of job satisfaction of non-managerial employees in the selected apparel organizations in Gampaha district, Sri Lanka.

Keywords: Extrinsic Rewards, Intrinsic Rewards, Gender, Age, Job Satisfaction.

\section{Introduction}

To achieve success and to gain maximum contribution, employee satisfaction is very important. Job satisfaction is one of the major concepts as well as one of the objectives that has to be accomplished in order to achieve strategic goals of HRM (Opatha 2012). Organizations are challenged, as they have to make employees' satisfied in their job and therefore organization will perform better and consequently will achieve their competitive 
edge (Jayarathna 2014). Employees often perceive his/her rewards as an income (Opatha 2012). David, Joseph and Williaam (1970) suggest that type of reward system under which workers performance strongly influence the employee satisfaction. Because of that, reward has been often mentioned as a motivator for performance and a determinant of job satisfaction (Jayarathna 2014). When a fair reward is not available current, appropriate employees may leave the organization and also it will affect to attract new persons as well (Opatha 2012). That's why in any organization, reward plays an important role in building and sustaining the commitment among employees that ensures a high standard and the superb reward package in an organization always helps to create employee satisfaction. This research is aimed to discuss the rewards and its impact on job satisfaction of non-managerial employees in the selected apparel organizations in Gampaha district.

\section{Problem Background and Problem of the Study}

Reward is a very vital factor that has a significant contribution towards enhancing the employee job satisfaction; as a result, organizations are continuously improving their reward system for retaining and becoming more productive for employees (Nazir et al. 2013). Further, these reward schemes are designed to promote a strong identity with corporate goals and used a range of individualized strategies, such as profit related pay, performance related pay and competency based schemes (Waring 2007). These rewards have a direct link with the motivation and job satisfaction of employees (Vijayakumar \& Subha 2013). Even though many researches have investigated that extrinsic and intrinsic rewards factors are very important to employee's career, no one has found to what extent each reward component affect employee job satisfaction. It is similar to employees' intention to leave. Therefore, by considering theoretical and empirical evidence it seems that there is a still gap in those two variables. Less research studies have done to investigate this in the Sri Lankan context. To fill this research gap, it is very essential to conduct a research study to identify the impact on various reward components to employee job satisfaction of non-managerial level employees in the apparel industry. Therefore problem of the study is addressed, the extent to which organizational reward components impact on job satisfaction of non-managerial employees in the apparel industry.

\section{Literature Review}

Rewards in current situation are playing a significant role to enhance job satisfaction of an employee whether he is working in any type of organization (Nazir et al. 2013). Bratton and Gold (2003) explained an employee receives payments in relation to contribution in an organization that may be cash, noncash and psychological are called rewards. Kalleberg (1977) stated that the word of reward state the benefits that employees receive from their jobs.

Buch and Tolentino (2006) mentioned that the concept of six sigma that indicates the four categories of rewards, that is intrinsic, extrinsic, social and the organizational remuneration. But as Williamson et al. (2007), reward distinguishes only three main types; they are extrinsic, intrinsic and social rewards. Bratton and Gold (1994) indicate that organizational reward means all the benefits i.e. financial and non-financial that an employee receives 
through their employment relationship with an organization. Extrinsic reward is defined as external to the job itself and explained that monetary rewards (Ozutku 2012) and further mentioned that extrinsic rewards comprise elements as pay, fringe benefits, job security, promotion, competitive salaries, incentives, merit bonuses. Intrinsic reward defined as internal feeling of an individual about themselves (Nazir et al. 2013). Ozutku (2012) classified intrinsic rewards as achievement, variety, challenge, autonomy, responsibility, personal and professional growth, recognition, praise from supervisors and co-workers.

When employee achieve their desired results from job so that, the desired achievement is called as job satisfaction (Brief \& Weiss 2002). According to Worrel (2004) an individual's positive affective reaction of the target environment as a result of the individual appraisal of extent to which his or her needs are fulfilled by the environment. For this study, job satisfaction can be well-defined as an individual's positive affective reaction of the target environment as a result of the individual appraisal of extent to which his or her needs are fulfilled by the environment (Worrel 2004).

Three dimensions of job satisfaction were similar as above that was mentioned by Luthans and Sommers (2004). They are, response towards work condition; work results fulfill expectations and related attitudes. Through the factors such as temperature, lighting, ventilation, hygiene, noise, working hours and resources are all part of working conditions. Response towards above factors can be measured through exit, neglect, voice and loyalty (Luthans \& Sommers 2004). Fulfill expectations or need fulfillment means that extent to which a job with its specified characteristics and duties allow an individual worker to meet his/her personal needs (Kinicki \& Kreitner 2007). Through organization citizenship behavior, pay, fairness and promotion used to measure the work result to fulfill expectations. Related attitudes mean perception of how fairly an individual is treated at work (Kinicki \& Kreitner 2007). And there are dimensions to determine attitudes towards job satisfaction. They are perceived organizational support and employee engagement.

According to Koustelious (2001) many personal characteristics affect job satisfaction in different and complex ways, among those personal characteristics are gender, age, marital and parental status and working experience. Many studies suggested a positive or none significance relationship of job satisfaction with age. For the study purpose consider effect of biological gender differences, that means male and female on relationship between reward and job satisfaction

\section{Research Framework}

Previous research proved that there is a strong relationship between organizational rewards and job satisfaction (Mathieu \& Zajac 1990). Figure 1 shows the organizational rewards impact on employee job satisfaction. 
Figure 1: Conceptual Model

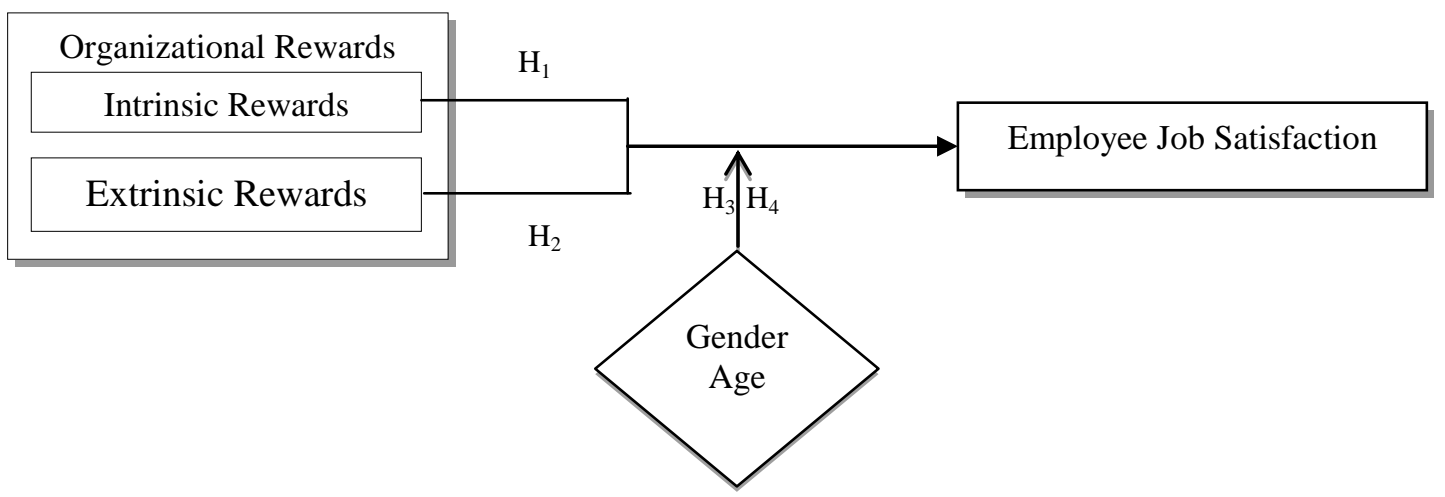

The use of intrinsic reward practices exhibited a significantly positive effect on job satisfaction (Ozutku 2012). The intrinsic reward refers to the motivation that comes from inside an individual (Armstrong 1988). Factors that influence intrinsic rewards which are concerned with the quality of work life, tend to have a long-term effect since they are inherent in individuals and not imposed from outside (Armstrong 1988). The first hypothesis $\left(\mathrm{H}_{1}\right)$ aims to find out the level of job satisfaction towards the intrinsic rewards of nonmanagerial employees in the apparel sector.

$H_{1}$ : There is a positive impact of intrinsic rewards on job satisfaction.

According to Ozutku (2012) job satisfaction was positive and significantly related to extrinsic rewards and Kalleberg (1977) mentioned high relationship between job satisfaction and extrinsic rewards. The level of job satisfaction towards the extrinsic reward of apparel sector could be different from the above mentioned relationships. The second hypothesis $\left(\mathrm{H}_{2}\right)$ aims to find out the level of job satisfaction towards the extrinsic rewards of non-managerial employees in the apparel sector.

$\mathrm{H}_{2}$ : There is a positive impact of extrinsic rewards on job satisfaction.

Furthermore, demographic variables like gender influence job satisfaction (Devaney \& Chen 2003) and gender has a significant moderating effect on the relationship between reward and job satisfaction (Calvo- Salguero et al. 2010). Gender is often concluded as an individual characteristic in studies of job satisfaction (Brief \& Aldag 1975; Oshagbemi 2000 cited in Koustelios 2001). Therefore, for this study third hypothesis $\left(\mathrm{H}_{3}\right)$ aims to find out that the differences between men and women giving moderating impact to reward and employee job satisfaction.

$H_{3}$ : Gender difference moderates the relationship between rewards and job satisfaction.

Age is one of characteristic which affects job satisfaction and many studies suggested a positive relationship between age and job satisfaction (Koustelios 2001). Some other researchers suggest U-shaped relationship or non-significant relationship between age and overall job satisfaction (Singh and Singh 1980). Therefore, for this study the fourth hypothesis $\left(\mathrm{H}_{4}\right)$ aims to find out the differences between age, giving moderating impact to the reward and employee job satisfaction.

$\mathrm{H}_{4}$ : Age difference moderates the relationship between rewards and job satisfaction. 


\section{Method}

\section{Research design}

This study was conducted in a quantitative design by collecting data through a questionnaire and the two variables were identified and tested based on the hypotheses developed. This study focuses on hypotheses testing and identifying correlation between variables. These types of studies usually explain the nature of certain relationships and explain the variance in the dependent variable. The target population of the study is the non-managerial employees in selected apparel organizations in Gampaha district. This research study focuses on the nonprobability sampling as there are many apparel firms in Sri Lanka and for the purpose of the study the researcher has only selected 100 front office employees from two apparel firms in Gampaha district. Sampling technique used for this study was the convenient sampling which refers to the collection of information from the members who are conveniently available to provide it.

\section{Measures}

In the method of measurement of the variable include the measurement of independent variable as intrinsic and extrinsic rewards and dependent variable as employee job satisfaction. The organizational rewards were measured by their responses to the questionnaires with five points Likert Scale, which was designed as strongly agree, agree, neutral, disagree and strongly disagree. All the questions are the scale for positive statement in the questionnaire. The dependent variable of the research was job satisfaction and it was measured (Kottawatta 2014) by their responses to the questionnaires with five point Likert scale for positive statements.

\section{Validity and Reliability}

The inter item consistency reliability was examined with Cronbach's Alpha test (Kottawatta 2014). This test was carried out using 30 responses of the non-managerial level employees. The results of Cronbach's Alpha test are given in Table 1, which suggest that the internal reliability of each instrument was satisfactory.

Table 1: Cronbach's alpha coefficients and variance explain

\begin{tabular}{|c|c|c|c|}
\hline & \multirow[t]{2}{*}{ Instrument } & Reliability & Validity \\
\hline & & Cronbach's alpha & Variance Explain \\
\hline 1 & Intrinsic rewards & 0.821 & 51.147 \\
\hline 2 & Extrinsic rewards & 0.974 & 88.864 \\
\hline 3 & Job satisfaction & 0.942 & 73.632 \\
\hline
\end{tabular}

The result of factor analysis of the validity of the questionnaire, which shows in Table 1 variance explains that more than 0.5 in each variable. The content validity of the variables of the study was ensured by the fact that the correlation and regression analysis support the hypotheses formulated. 


\section{Techniques of Data Analysis}

The data collected from primary (questionnaire) source were analyzed using the computer based statistical data analysis package, SPSS (Version 16.0) for validity, reliability and relationship testing. The data analysis included univariate and bivariate analysis.

\section{Results}

The frequency distribution analysis was made individually for the variables of organizational rewards as intrinsic rewards and extrinsic rewards. Summary of the dependent and independent variables of the study is shown in Table 2.

Table 2: Frequency Distribution Analysis of Variables

\begin{tabular}{|l|r|r|r|}
\hline Statistics & Intrinsic Rewards & Extrinsic Rewards & Job Satisfaction \\
\hline Mean & 3.58 & 3.39 & 3.57 \\
\hline 5\% Trimmed Mean & 3.39 & 3.16 & 3.63 \\
\hline Median & 3.7273 & 3.5714 & 3.7 \\
\hline Variance & 0.175 & 0.437 & 0.462 \\
\hline Std. Deviation & 0.418 & 0.661 & 0.679 \\
\hline Minimum & 2.09 & 1.14 & 1.4 \\
\hline Maximum & 4.09 & 4.14 & 4.6 \\
\hline Range & 2.0 & 3.00 & 3.2 \\
\hline Interquartile Range & 0.27 & 0.29 & 0.4 \\
\hline Skewness & -2.11 & -2.24 & -1.702 \\
\hline Kurtosis & 4.083 & 4.707 & 2.903 \\
\hline
\end{tabular}

The independent variable of intrinsic rewards mean value was very close to 3.59 . On a five point Likert scale mean value should be $3(1+2+3+4+5=15 / 5)$. Resulted mean value is higher than the standard mean value. It indicates that most of the respondents have given quite true answers. 95\% confidence level mean value was close to 4 . The central value of the sample of the extrinsic rewards was close to 3.39. And 95\% confidence level mean is close to 3.16. The mean value was more than 3; hence the data distribution of the sample was good. The dependent variable of job satisfaction mean value was very close to 3.57. Resulted mean value is higher than the standard mean value. It indicates that the most of the respondents have given quiet true answers.

The correlation analysis and simple regression analysis were used to investigate the relationship between independent variables of intrinsic and extrinsic rewards and the dependent variables of job satisfaction. Using Pearson's correlation with two tailed test, find a correlation between two continuous variables. Results of Pearson's correlation are shown in Table 3. 
Table 3: Correlation Analysis

\begin{tabular}{|l|r|r|r|r|}
\hline & Job Satisfaction & Intrinsic Reward & Extrinsic Reward & Total Reward \\
\hline Job Satisfaction & 1 & $.821^{* *}$ & $.901^{* *}$ & $.914^{* *}$ \\
Sig. (2-tailed) & .000 & .000 & .000 & .000 \\
\hline Intrinsic Reward & & 1 & $.777^{* *}$ & $.942^{* *}$ \\
Sig. (2-tailed) & .000 & .000 & .000 \\
\hline Extrinsic Reward & & 1 & $.943^{* *}$ \\
Sig. (2-tailed) & & & .000 & .000 \\
\hline Total Reward & & & 1 \\
Sig. (2-tailed) & & & & .000 \\
\hline
\end{tabular}

**. Correlation is significant at the 0.01 level (2-tailed).

The Pearson correlation between the two variables is $0.914(\mathrm{p}=0.000)$, which is positive. It shows that there is a strong positive relationship between total organizational rewards and employee job satisfaction. When the total organizational rewards increase, it increases employee job satisfaction. Intrinsic rewards, extrinsic rewards and total organizational rewards have a highly positive relationship individually. These Pearson correlations are $0.942(\mathrm{p}=0.000)$ and $0.943(\mathrm{p}=0.000)$ in respectively. Accordingly, there are $0.77(\mathrm{p}=0.000)$ Pearson correlations between intrinsic rewards and the extrinsic rewards. There is 0.821 $(\mathrm{p}=0.000)$ and $0.901(\mathrm{p}=0.000)$ correlation between intrinsic rewards and extrinsic rewards on employee job satisfaction. The entire variables are correlated positively. This means that when one of the variables increases, it causes to increase employee job satisfaction.

Table 4: Regression Analysis on Extrinsic \& Intrinsic Rewards and Job Satisfaction

\begin{tabular}{|c|c|c|c|c|c|}
\hline & B constant & $\beta$ value & R Square & F & Sig. \\
\hline Extrinsic reward & -1.208 & .821 & .675 & 167.9 & $.000^{\mathrm{a}}$ \\
\hline Intrinsic Rewards & .503 & .901 & .812 & 350.3 & $.000^{\mathrm{a}}$ \\
\hline
\end{tabular}

The regression analysis results are presented in above summary and it (Table 4) explains that employee job satisfaction is increased by 0.821 points for each additional increase in intrinsic rewards, which is significant at $5 \%(\mathrm{p}=0.000)$. And employee job satisfaction is increased by 0.901 points for each additional increasement in extrinsic rewards, which is significant at $5 \%$ $(p=0.000)$. According to the results of test, the hypothesis is accepted since $p<0.01$. Hence the data support the hypothesis that there is an impact of intrinsic and extrinsic rewards on employee job satisfaction of non-managerial level employees in the selected apparel organization in Gampaha district.

Moderated regression analysis indicates there is a moderator effect of gender to the organizational rewards and employee job satisfaction. Table 5 shows the summary of regression analysis on gender as moderate factor. 
Table 5: Regression Analysis of Gender as a Moderating Factor

\begin{tabular}{|l|r|r|}
\hline & Model 1 $(\beta)$ & Model 2 $(\beta)$ \\
\hline All factor & $0.912^{* *}$ & \\
Gender & 0.071 & \\
\hline All factor & & $0.900^{* *}$ \\
Gender & & 0.044 \\
All factor* Gender & & 0.31 \\
\hline R & 0.923 & 0.923 \\
\hline R Square & 0.852 & 0.852 \\
\hline Adjusted R Square & 0.848 & 0.846 \\
\hline F & 230.3 & 151.6 \\
\hline Sig. & 0.106 & 0.927 \\
\hline
\end{tabular}

**. Correlation is significant at the 0.01 level (2-tailed).

The regression analyses results can be presented as follow for the test hypothesis, the model $1, \mathrm{P}=.0 .106$ and model 2, $\mathrm{p}=0.927$. According to the results, the test hypothesis is not accepted since $\mathrm{p}>0$, as well as $\mathrm{F}$ value is 151.6 , which is not significant. Therefore the data weakly supported the hypothesis of the gender difference moderate relationship between organizational rewards and job satisfaction of non-managerial level employees in the selected apparel organization in Gampaha district.

Table 6: Regression Analysis of Age as a Moderating Factor

\begin{tabular}{|l|r|r|}
\hline & Model 1 $(\beta)$ & \multicolumn{1}{|c|}{ Model 2 $(\beta)$} \\
\hline All factor & $0.920^{* *}$ & \\
& -0.044 & $1.145^{* *}$ \\
All factor & & 0.456 \\
Age & & -0.547 \\
All factor* Age & & 0.923 \\
\hline R & 0.0 .921 & 0.852 \\
\hline R Square & 0.849 & 0.847 \\
\hline Adjusted R Square & 0.845 & 151.8 \\
\hline F & 224.9 & 0.195 \\
\hline Sig. & 0.319 & \\
\hline
\end{tabular}

**. Correlation is significant at the 0.01 level (2-tailed).

The regression analysis results can be presented as follows for the age test hypothesis. The model $1, \mathrm{P}=.0 .319$ and model $2, \mathrm{p}=0.195$. According to the results, the test hypothesis is not accepted since $\mathrm{p}>0$, as well as $\mathrm{F}$ value is 151.8 , which is not significant. The data weakly upkeep the hypothesis of age difference moderate relationship between organizational rewards and job satisfaction of non-managerial level employees in the selected apparel organization in Gampaha district.

\section{Discussion and Conclusion}

It was found that there is a positive impact of intrinsic rewards on employee job satisfaction of non-managerial employees in the apparel sector. The correlation between these variables was 0.821 , which is significant at 0.000 levels and positive impact of extrinsic rewards on employee job satisfaction of non-managerial employees in the apparel sector. The correlation between these variables was 0.901 , which is significant at 0.000 levels. According to the 
results of the simple regression analysis, intrinsic rewards found to have a positive impact on job satisfaction with the strength of $\beta$ value of 0.821 , significant at 0.000 . This explains that employee job satisfaction increase by 0.821 points for each additional increase in intrinsic rewards. The findings of correlation and regression analysis empirically confirm the arguments given by Driscoll and Randall (1999). They argued that intrinsic rewards will probably lead to job satisfaction. Ozutku (2010) mentioned that intrinsic rewards are instrumental in shaping people results and therefore manufacturing firms identify performance related rewards and develop appropriate reward programs to reinforce and satisfy employees in order to achieve expected results.

It was found that there is a positive impact of extrinsic rewards on employee job satisfaction of non - managerial employees in the apparel sector. The correlation between these two variables was 0.901 , which is significant at 0.000 levels. According to the results of the simple regression analysis, extrinsic rewards found to have a positive impact on job satisfaction with the strength of $\beta$ value of 0.901 (significant at 0.000 ). This finding is confirmed by Williamson et al. (2007). And they argued that extrinsic reward is something that is done to or for people to motivate them that arise from factors outside an individual, such as money, grades, criticism or punishment. As Rafiq et al. (2012) and Kalleberg (1977), there is a high relationship between employee job satisfaction and extrinsic rewards. However, this finding is not matched with the finding of Jayarathna (2014). He found that there is negative relationship between extrinsic rewards and job satisfaction.

According to the regression analysis, gender and age demonstrate that $\beta=0.31$ and $\beta=$ -0.547 ( $\beta$ value -0.195 ) which were more than $p<0.05$. This means that model cannot be used gender and age for predicting the moderate impact of organizational rewards and employee job satisfaction. As Brief and Aldag (1975), Oshagbemi in 2000 cited in Koustelios (2001), gender is often concluded as individual characteristics in studies of job satisfaction. However, there are no conclusive findings with regard to the levels of job satisfaction between male and female have been found. The contradictory view was given by Devaney and Chen (2003) and Calvo-Salguero et al. (2010). As Koustelios (2001), age is one of the characteristic which affects job satisfaction and many studies suggested a positive relationship between age and job satisfaction. However, some other studies suggested the Ushape relationship or non-significant relationship between age and overall job satisfaction (Singh and Singh 1980).

\section{Recommendations}

From the empirical findings, it can be implied that apparel sector organizations should give highl consideration towards extrinsic rewards in order to increase employee job satisfaction. Not only that, but also intrinsic rewards is instrumental in shaping employees results. Management should identify performance related rewards and develop appropriate reward programs to reinforce these non-managerial employee results. The knowledge of the significant relationship between job satisfaction and intrinsic and extrinsic rewards should be employed in designing and fixing of rewards. 
Further the researcher recommended for the future studies to examine the extent to which social rewards that means the relationship between supervisors, the relationship between coworkers and the effective communication between all the parties will affect employee job satisfaction. Because psychologically every employee expect favorable support from their organizations. The present research was conducted only for non-managerial level employees. This could be extended into many more categories and would give a more realistic picture.

\section{References}

i. Armstrong, M \& Murlis, H 1998, Reward management: Handbook of remuneration strategy and practice.

ii. Bratton, J \& Gold, J 1994, 'Human resource management: theory and practice', Basinghstoke: Macmillan.

iii. Bratton, J \& Gold, J 2003, 'Human resource management: Theory and practice', eds 3, New York: Palgrave Macmillan.

iv. Brief, AP \& Weiss, HM 2002, 'Organizational behavior: Affect in the workplace', Annual Review of Psychology, Vol. 53, pp. 279-307.

v. Buch, K \& Tolentino, A 2006, 'Employee perception of the rewards associated with six sigma', Journal of organization Change Management, Vol. 19, No. 3, pp. 356364.

vi. Calvo-Salguero, A 2010, 'Relationship between work- family conflict and job satisfaction: The moderating effect of gender and salience of family and work roles', African Journal of Business Management, Vol. 4, No. 7, pp.1247-1259.

vii. David, FJ \& William, K 1970, 'Job Satisfaction Commitment', Irwin: Illions.

viii. DeVaney, SA \& Chen, ZS 2003, 'Job Satisfaction of recent graduates in Financial services, US Department of Labour', Bureau of Labour Statistics, Compensation and Working Conditions. http://www.bls.gov/opub/cwc/cm20030522ar01p1.htm

ix. Jayarathna, SMDY 2014, 'Impact of reward management and decision making on job satisfaction', International Journal of scientific Engineering, Vol. 3, No. 3, pp. 146153.

x. Kalleberg, AL 1977, 'Work values and job rewards: A theory of job satisfaction', American Sociological Review, Vol. 42, pp.124-143.

xi. Kinicki, A \& Kreitner, R 2007, Organizational Behaviour, New York.

xii. Kottawatta, H 2014, Research guide book, Department of Human Resource Management, Colombo.

xiii. Koustelios, AD 2001, 'Personal characteristics and job satisfaction of Greek teachers', The International Journal of Educational Management, Vol. 15, No. 7, pp. 354-358.

xiv. Luthans, KW \& Sommers SM 2004, 'The impact of high performance work on industry level outcomes', Journal of Managerial Issues, Vol. 17, No. 3, pp. 327-345.

xv. Mathieu, JE \& Zajac, DM 1990, 'A review and meta-analysis of the antecedents, correlates and consequences of organizational commitment', Psychological Bulletin, Vol. 108, No. 2, pp. 171-194. 
xvi. Nazir, T, Khan, SUR, Shan, SYH \& Zaman, K 2013, 'Impact of rewards and compensation on job satisfaction', Middle East Journal of Scientific Research, Vol. 14, No. 3, pp. 394-403.

xvii. Opatha, HHDNP 2012, Human resource management, Sri Lanka.

xviii. Ozutku, H 2012, 'The influence of intrinsic and extrinsic rewards on employee results: An empirical analysis in Turkish manufacturing industry', Business and Economics Research Journal, Vol. 3, No. 3, pp. 29-48.

xix. Rafiq, M, Javed, M, Khan, M \& Ahmed, M 2011, 'Effect on rewards on job satisfaction: Evidence from Pakistan', International Journal of Business and Behavioural Sciences, Vol. 2, No. 6, pp. 22-30.

xx. Singh, S \& Singh, A 1980, 'The effect of certain social and personal factors on the job satisfaction of supervisors', Psychological studies, Vol. 25, pp.129-132.

xxi. Vijayakumar, VTR \& Subha S 2013, 'Impact of rewards and recognition on employee job satisfaction and motivation in private banks of tirunelveli city', International Research Journal of Business Management, Global Wisdom Research Publications, Vol. 5, pp.64-73.

xxii. Waring, MA 2007, 'Geographies of knowledge, geometrics of power: framing the future of the higher education', The world yearbook of education, Routledge London and New York.

xxiii. Williamson, IO, Burnett, MF \& Bartol, KM 2007, 'The interactive effect of collectivism and organizational rewards on effective organizational commitment', Cross Cultural Management: An International Journal, Vol. 16, pp. 28-43.

xxiv. Worrell, TG 2004, 'School psychologists' job satisfaction: ten years later', Dissertation submitted to the faculty of the Virginia polytechnic institute and state university.

\section{Sankalpana, WS}

Department of Human Resource Management, University of Sri Jayewardenepura

Jayasekara, $\mathbf{P}$

Senior Lecturer, Department of Human Resource Management, University of Sri Jayewardenepura 